\title{
Ignition and Flame Characteristics of Cryogenic Hydrogen Releases
}

Pratikash P. Panda ${ }^{* a}$ and Ethan S. Hecht ${ }^{\mathrm{a}}$

\author{
${ }^{a}$ Combustion Research Facility, Sandia National Laboratory, Livermore, California, USA \\ *Corresponding Author Email: pppanda @ sandia.gov \\ Address: Combustion Research Facility, Sandia National Lab, MS 9052, 7011 East Avenue, \\ Livermore, California, USA, Phone No. (925)-294-6737
}

\begin{abstract}
In this work, under-expanded cryogenic hydrogen jets were investigated experimentally for their ignition and flame characteristics. The test facility described herein, was designed and constructed to release hydrogen at a constant temperature and pressure, to study the dispersion and thermo-physical properties of cryogenic hydrogen releases and flames. In this study, a nonintrusive laser spark focused on the jet axis was used to measure the maximum ignition distance. The radiative power emitted by the corresponding jet flames was also measured for a range of release scenarios from $37 \mathrm{~K}$ to $295 \mathrm{~K}, 2$ - 6 bar $_{\text {abs }}$ through nozzles with diameters from $0.75-$ $1.25 \mathrm{~mm}$. The maximum ignition distance scales linearly with the effective jet diameter (which scales as the square root of the stagnant fluid density). A 1-dimensional (stream-wise) cryogenic hydrogen release model developed previously at Sandia National Laboratories (although this model is not yet validated for cryogenic hydrogen) was exercised to predict that the mean mole fraction at the maximum ignition distance is approximately 0.14 , and is not dependent on the release conditions. The flame length and width were extracted from visible and infra-red flame images for several test cases. The flame length and width both scale as the square root of jet exit Reynolds number, as reported in the literature for flames from atmospheric temperature
\end{abstract}


hydrogen. As shown in previous studies for ignited atmospheric temperature hydrogen, the radiative power from the jet flames of cold hydrogen scales as a logarithmic function of the global flame residence time. The radiative heat flux from jet flames of cold hydrogen is higher than the jet flames of atmospheric temperature hydrogen, for a given mass flow rate, due to the lower choked flow velocity of low-temperature hydrogen. This study provides critical information with regard to the development of models to inform the safety codes and standards of hydrogen infrastructure.

Keywords: Under-expanded jets, Hydrogen safety, Cryogenics, Laser spark ignition, Radiation 


\subsection{Introduction}

Widespread hydrogen use as an alternative fuel for vehicles will require significant infrastructure investments to accommodate increased bulk transport, delivery, and storage of hydrogen. Due to the high density of hydrogen in its liquid phase, fueling stations that store cryogenic hydrogen have been shown to be economically favorable in a future hydrogen economy [1]. The desire to site hydrogen fueling infrastructure for Fuel Cell Electric Vehicles (FCEV) in urban and suburban areas drives an interest in placing bulk cryogenic hydrogen storage in space-constrained sites. This storage requirement contrasts with traditional industrial uses of flammable cryogens, for which the safety codes were developed, that are not as spaceconstrained and can accommodate large safety separation distances. Liquid hydrogen bulk storage separation distances from the current, 2016 edition of National Fire Protection Agency Hydrogen Technologies Code (NFPA 2) [2] for lot lines, building openings or air intakes are in some cases more than twice as large as similar bulk gaseous storage systems. Safety for hydrogen infrastructure is of utmost importance, but the current prescriptive liquid hydrogen separation distances are based on subjective expert opinion rather than physical models, and thus may be overly conservative.

Codes and standards development that governs the storage and transport of liquid hydrogen requires a thorough understanding of release and dispersion characteristics, along with flammability and radiation heat transfer over a range of realistic scenarios and environmental conditions [3]. It is also important to consider specific activities when developing codes and standards, such as repeated fuel transfer connections being made and broken. Most hydrogen releases are expected to be highly turbulent and heavily influenced by buoyancy. Cryogenic hydrogen dispersion can be affected by flashing, multi-phase flows, heat transfer, pool 
formation, ambient conditions (e.g., temperature, humidity, wind), ground effects, and obstacles/barriers. Extreme cold temperatures can also condense or even freeze ambient air during spills, which differentiates these releases from those of liquid natural gas and can result in unique hazards that likewise need to be understood [4-5]. A review of hydrogen system safety knowledge by Kotchourko et al. [6] includes a detailed discussion of liquid hydrogen systems. Several research priorities and knowledge gaps were identified to enable accurate modelling of liquid hydrogen releases for safety analyses. These include two-phase releases, dispersion of cryogenic and $\mathrm{LH}_{2}$ in enclosures, physical properties of $\mathrm{LH}_{2}$, effect of turbulence and, buoyancy on heat transfer between cold hydrogen and ambient air and experiments that can provide a closure to these issues. Hall et al. [7], reported experimental studies to establish the severity of an ignition from a release of $\mathrm{LH}_{2}$, with spill rates consistent with a transfer hose operation. Based on the radiation heat flux measurements they created a safety distance guide which only corresponds to their hydrogen spillage rate. While these and several other large scale studies have looked at the pooling and vaporization of hydrogen [4-8], these experiments are sparsely instrumented with poor control of some boundary conditions. Accordingly, there is the risk that the use of improperly validated models to establish safety envelopes could be detrimental to the emergence of hydrogen as a transportation fuel.

In a controlled laboratory conditions, Friedrich et al. [9] performed release and combustion experiments for cryogenic hydrogen jets with release temperatures between $34-65$ $\mathrm{K}$ and pressures from $0.7-3.5 \mathrm{MPa}$ in the ICESAFE (Integrated Cable Energy Safety Analysis Facility and Equipment) facility located at the Karlsruhe Institute of Technology. Hydrogen concentration decay rate measurements preserved the linear dependence when plotted against a density-scaled release diameter. For ignited cryogenic hydrogen jets, the operation states for 
three possible flame modes were schematically mapped: 1) ignition with flash-back to the release nozzle followed by a stable jet flame, 2) a stable lifted flame without flash-back, and 3) a transient burn with subsequent blow-off. For the jet flames examined, no overpressure or noise hazards were observed. Outside of these experiments, there is a dearth of data in wellcharacterized environments. Thus, experimental data from well-controlled experiments with high-fidelity diagnostics are necessary to generate parametric databases that can be leveraged for model development and validation [10].

The goal of this work is to advance the scientific understanding of the thermo-physical characteristics of cryogenic hydrogen releases and flames to the point where codes and standards can be informed by the physics of these phenomena. A cryogenic hydrogen release facility was designed, constructed and used in this work to simulate leak scenarios from a liquid hydrogen storage system. The experimental facility was designed for a controlled, steady-state release at fixed pressure and temperature. In future experiments, the dispersion properties will be characterized using advanced laser diagnostics such as filtered planar laser Rayleigh scatter, capable of accurate instantaneous hydrogen concentration measurements, and complementary flow velocity measurements using particle image velocimetry. Within the laboratory, similar experiments have been performed on high-pressure gaseous hydrogen releases [11-14], leading to modifications of NFPA 2.

As discussed by LaChance et al. [15], the radiant heat flux from a jet flame is a critical parameter that governs the deterministic separation distance (or the hazard distance) to prevent harm during an accident scenario. An understanding of the ignition distance, which is related to the local fuel mass fraction, can inform other separation distances, such as the distance hydrogen infrastructure should be kept from ignition sources (e.g., power lines). In the present study, cold 
(as low as $37 \mathrm{~K}$ ) hydrogen releases formed under-expanded jets that were subsequently ignited with the help of a laser generated spark. A maximum ignition distance $\left(X_{i g n}\right)$, which is defined as the maximum distance from the nozzle exit at which a laser spark causes upstream flame propagation leading to a sustained jet flame, was measured. The radiative power from the sustained turbulent diffusion jet flames was measured using radiometers. We have developed correlations such that the flow variables can be used to calculate the maximum ignition distance and radiant heat flux from ignited flames of cryogenic, under-expanded hydrogen jets.

\subsection{Cryogenic Hydrogen Release Experimental System}

Cryogenic hydrogen release experiments were performed at the Turbulent Combustion Laboratory at Sandia National Laboratories. Liquid hydrogen tanks store hydrogen at fairly low

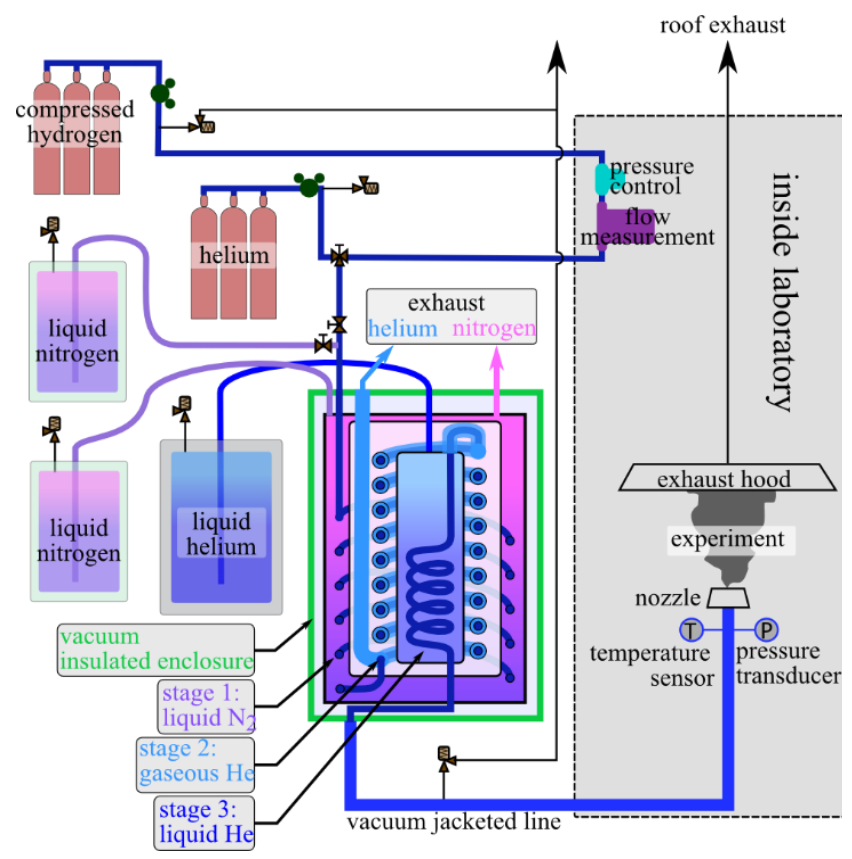

Figure 1. Sketch of the cryogenic hydrogen release experiment at the Turbulent Combustion Laboratory, Sandia National Laboratories. 
pressure (usually 3-5 bar), at the saturated liquid temperature $\left(28 \mathrm{~K}\right.$ at 6 bar $_{\text {abs }}$ and $23 \mathrm{~K}$ at 2 bar $\left._{a b s}\right)$; the cryogenic hydrogen release experiment was designed to simulate these conditions. A sketch of the cryogenic hydrogen release experimental system is shown in Fig. 1. During experiments, gaseous hydrogen flowed into the laboratory through a Tescom 44-3200 series pressure regulator followed by a Teledyne-Hastings (HFM-D-301) mass flow meter. This allowed independent regulation of the pressure while measuring the mass flow rate of hydrogen as a gas. Hydrogen flowed back outside the lab and into a vacuum insulated three-stage heat exchanger, constructed by Meyer Tool \& Mfg. Inc. Coiled stainless steel tubing dipped inside a bath of liquid nitrogen in the first stage of the heat exchanger cooled the hydrogen to around 80 K. In the second stage, the cold gaseous helium from the third stage exhaust further cooled the hydrogen in a counter-flow tube-in-tube heat exchanger. Finally, the precooled gaseous hydrogen flowed through a bath of liquid helium where it was cooled down to the saturation temperature. Hydrogen temperatures inside the heat exchanger were monitored with silicon diode temperature sensors installed at the inlet and exits of stages one and three, and liquid level sensors indicated the height of cryogen baths in the first and third stages of the heat exchanger. The saturated hydrogen flowed through a vacuum jacketed line into the laboratory. A silicon diode temperature sensor and a pressure transducer (Omega PX 419-150GI) near the release point were used to monitor the exit conditions. The hydrogen was released in the lab through a small interchangeable orifice $(0.75 \mathrm{~mm}, 1 \mathrm{~mm}$ and $1.25 \mathrm{~mm}$ diameter $)$. All gases and products of combustion were collected by an active laboratory exhaust system and expelled outside. A three-way valve upstream of the heat exchanger allowed the user to switch between gaseous hydrogen and helium flowing through the experimental system. This valve allowed users to purge the lines, extinguish flames, and served as a safety feature of the experiment. If hydrogen 
was detected by one of several flammable gas sensors in the laboratory, this solenoid valve would switch, flowing helium rather than hydrogen through the heat exchanger, vacuum jacketed line, and nozzle. This active purge prevented the back-flow and freezing of air in the cold lines under an alarm condition. A LabVIEW program was used for data acquisition and experimental control.

A systematic operating procedure was developed to operate the cryogenic release experiments. The heat exchanger tubing and the vacuum jacketed lines were first purged with gaseous helium. Liquid nitrogen was then used to precool the heat exchanger and lines all the way up to the release point while liquid nitrogen also filled the stage 1 bath. Finally, while gaseous hydrogen flowed, the heat exchanger was operated with liquid helium in stage 3, cooling hydrogen down to the saturation temperature while monitoring the temperature at the exit point. For steady-state operation at a constant temperature below $50 \mathrm{~K}$ at the nozzle, approximately 3 hours were required. The heat transfer from the initially warm vacuum jacketed line to the cold $\mathrm{H}_{2}$ flow was responsible for long duration to achieve temperatures below $50 \mathrm{~K}$ at the nozzle. All the gaseous hydrogen was released inside the laboratory and vented through the active exhaust hood during the cool down procedure. The experimental operating conditions for the under-

Table 1. Cryogenic under-expanded hydrogen jet release experiment operating conditions.

\begin{tabular}{|c|c|}
\hline Pressure $\left(\right.$ bar $\left._{\mathrm{abs}}\right)$ & $2.0-6.0$ \\
\hline Temperature $(\mathrm{K})$ & $37-295$ \\
\hline Diameter $(\mathrm{mm})$ & $0.75,1.00,1.25$ \\
\hline $\mathrm{H}_{2}$ mass flow rate $(\mathrm{g} / \mathrm{s})$ & $0.1-0.7$ \\
\hline
\end{tabular}

expanded cryogenic hydrogen jets are summarized in Table 1. The range of nozzle exit pressures was $2-6$ bar, the temperature varied from $37-295 \mathrm{~K}$, and the nozzle orifices were switched between a $0.75,1.00$ and $1.25 \mathrm{~mm}$ diameter. A total of 140 data points of maximum 
ignition height were collected across the range of pressure, temperature and nozzle exit diameters.

The mass flow rate was calculated, assuming isentropic expansion from the measured nozzle pressure and temperature to the sonic choked flow velocity through the small orifice, using a real gas equation of state [16]. A comparison between the experimentally measured and calculated mass flow rate of $\mathrm{H}_{2}$ for all the test cases is shown in Fig. 2. For most of the conditions the measured mass flow rate is the same as the calculated flow rate. There are some

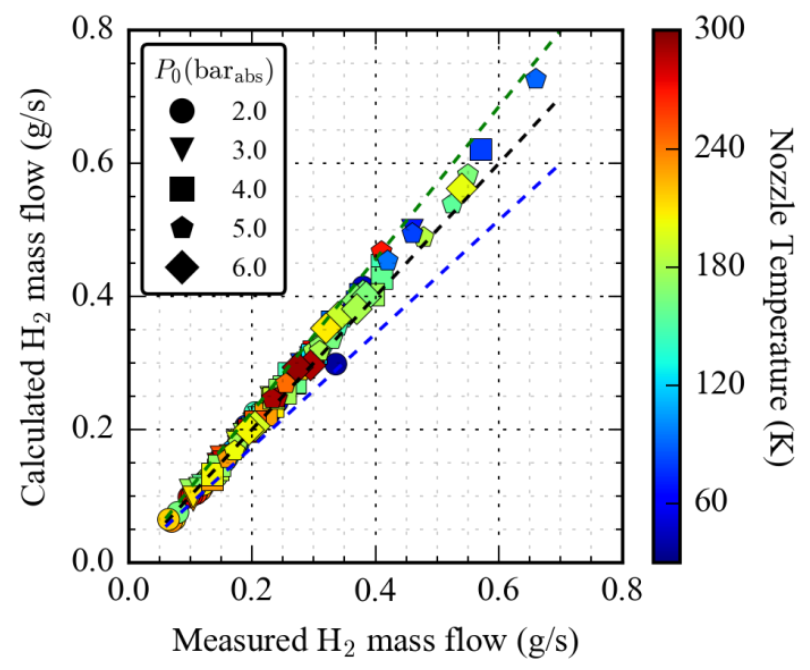

Figure 2. Calculated mass flow rate from the ignition experiments as a function of measured mass flow rate. Black dashed line is the 1:1 comparison, blue and green dashed lines show the $\pm 10 \%$ boundary.

slight deviations at higher pressures and colder jet temperatures; no more than $10 \%$ error for the conditions studied.

A laser spark ignition system was used to determine the maximum ignition distance of the cryogenic under-expanded hydrogen jets. An $8 \mathrm{~mm}$ beam from a Nd:YAG laser (9-ns pulse duration, $100-\mathrm{mJ} /$ pulse, 532-nm wavelength) was focused using a spherical plano-convex ( $\mathrm{f}=$ $300 \mathrm{~mm}$ ) lens, to form a plasma channel that was roughly $1 \mathrm{~mm}$ in diameter and $4 \mathrm{~mm}$ long. The 
centroid of the laser spark plasma channel was aligned to the jet centerline. From Phuoc and White [17] it was determined that the laser energy was sufficient such that even the leanest or richest flammable hydrogen/air mixtures would be ignited. At each spark location, up to 75 laser spark were generated $(5$ seconds at $15 \mathrm{~Hz}$ ). The hydrogen release apparatus was installed on a translation stage and was translated vertically until a sustained jet flame was established at the maximum ignition distance.

\subsection{Results and Discussions}

\subsection{Maximum Ignition Distance}

Several measurement campaigns were performed to measure the maximum ignition distance of under-expanded cryogenic hydrogen jets. The maximum ignition distance $\left(X_{i g n}\right)$ depends on the hydrogen pressure, temperature, and leak diameter. Figure 3 shows a scatter plot of the maximum ignition distance as a function of hydrogen mass flow rate. The symbols here represent the nozzle pressures and the color of the symbol denotes the hydrogen temperature at the release point. It is evident from the plot that for a given mass flow rate of hydrogen the maximum ignition distance is larger for colder jets. Alternatively, a maximum ignition height is achieved at a lower mass flow rate of hydrogen for the colder jets.

Ricou and Spalding [18] reported that for momentum dominated axisymmetric jets of non-uniform density, the entrained mass flow increases with distance from the nozzle exit, scaling inversely by the square root of the density of the jet at the nozzle. Han and Mungal [19] observed a similar trend in the entrainment rate for turbulent reacting jets, albeit with a developing entrainment coefficient. The mass flow rate $(\dot{m}(x))$ at any point along the axis of the jet is given by

$$
\frac{\dot{m}(x)}{\dot{m}_{\mathbf{0}}}=C \frac{x}{D} \sqrt{\frac{\rho_{\infty}}{\rho_{\mathbf{0}}}}
$$




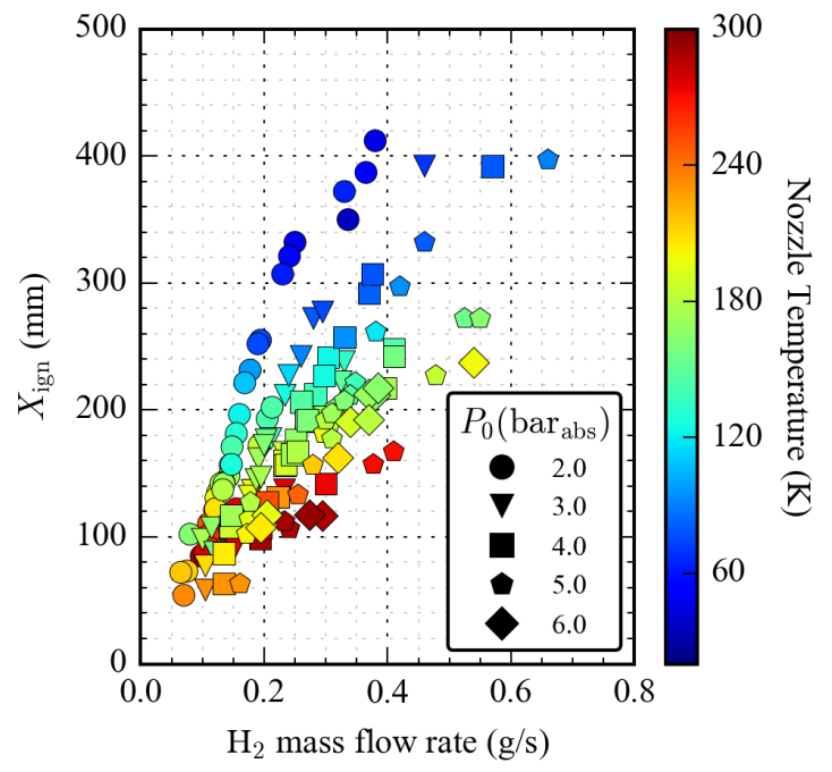

Figure 3. Maximum ignition distance as a function of mass flow rate for all the nozzle pressure, temperature and diameters studied.

where $\dot{m}_{0}$ is the initial mass flow rate (through the orifice), $C$ is an entrainment constant $(0.32$ for non-reacting, isothermal jets), $x$ is the distance from the release point along the jet axis, $D$ is the nozzle diameter, $\rho_{\infty}$ is the density of the entrained gas, and $\rho_{o}$ is the stagnation density of the released gas. The quantity $D \sqrt{\frac{\rho_{0}}{\rho_{\infty}}}$ is often called an effective diameter, $D_{\text {eff }}$ for an underexpanded jet. The effective diameter is the diameter through which the jet mass flow rate $\dot{m}_{0}$ would pass at atmospheric pressure to give the same momentum flux as the under-expanded jet at the nozzle exit. Li et al. [20], in a recent study of under-expanded hydrogen jets, confirmed that the variation of mean hydrogen mass fraction along the jet centerline depends on the effective diameter of the jet in the momentum dominated regime.

Depending on the local fuel mass fraction, an ignition kernel formed at a particular location could propagate towards the release source leading to a sustained jet flame [21-22]. In the current study, the maximum ignition distance at which a sustained jet flame could be 
established was found to scale with the effective diameter of the jet. Figure 4 shows this correlation, with the maximum ignition distance plotted against the effective diameter. Once again, the symbols represent the pressure and the color represents the temperature at the nozzle. The scatter plot of maximum ignition distance for all of the test cases now collapses, with a linear dependence on the effective diameter. Some of the data on maximum ignition distances for under-expanded hydrogen jets reported in the literature [13, 21, 23], are compared with the current data set in the figure, with operating conditions and maximum ignition heights shown in Table 2. Friedrich et al. [9] reported that the maximum ignition distance leading to a jet flame for cryogenic hydrogen jets can be expressed by the relationship $X_{i g n}=0.639 D \sqrt{\rho_{0} / \rho_{\infty}}$. This correlation is shown as the blue dashed line in Fig. 4. It is unclear why this correlation from Friedrich et al. [9] is so conservative, over-predicting the maximum ignition distance for the conditions from the current experimental data as well as other reported data [13, 21,23].

The key differences are that an intrusive jet engine electrical ignitor was used rather than the non-intrusive laser spark, and the jets were oriented horizontally as compared to the vertical jets $\mathrm{n}$ this work. While there may have been some flame stabilization on the ignitor, flow disruption from the ignitor, and buoyancy influence on flame propagation, it is unlikely that these effects would lead to the nearly factor of two difference in ignition distance. A new

Table 2. Operating conditions and the maximum ignition height reported by different research groups.

\begin{tabular}{|c|c|c|c|c|}
\hline Literature Data & $T(\mathrm{~K})$ & $P(\mathrm{bar})$ & $D(\mathrm{~mm})$ & $X_{\text {ign }}(\mathrm{mm})$ \\
\hline Ruggles et al. [13] & 295 & 9.89 & 1.5 & 365 \\
\hline Schefer et al. [21] & 295 & 1.0 & 1.91 & 126 \\
\hline Veser et al. [23] & 290 & 5 & 4 & 800 \\
\hline
\end{tabular}




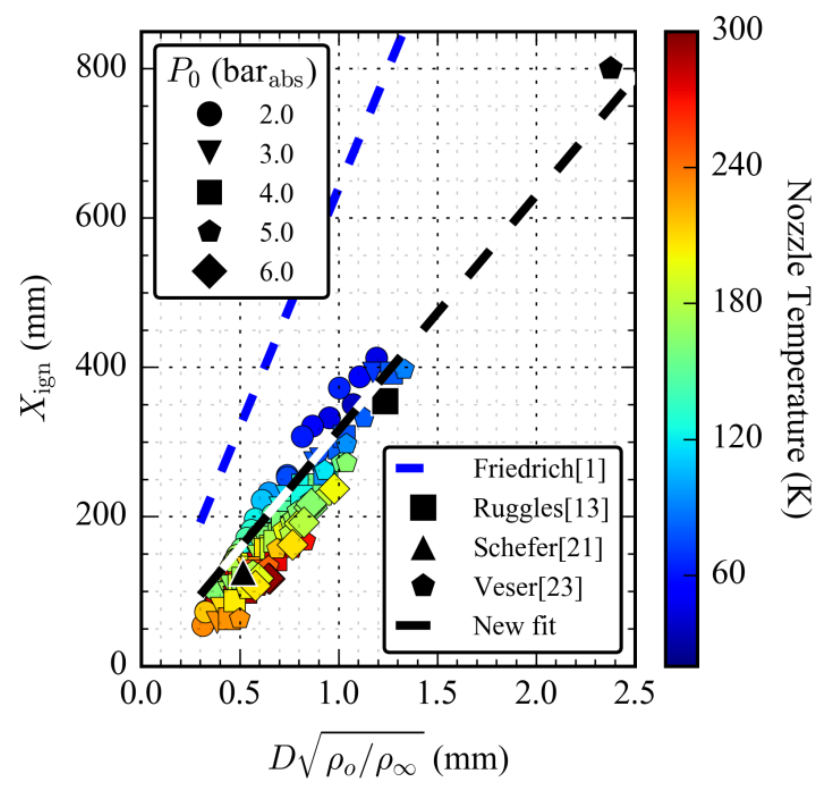

Figure 4. Maximum ignition distance as a function of effective diameter, for the cryogenic hydrogen releases in the current study and data from the literature. Blue dashed line shows a correlation from Friedrich et al. [9] and the black dashed line is a modified correlation proposed in this work.

correlation shown in the plot is a good fit for current data set as well as the reported values in the literature, given by

$$
X_{i g n}=0.316 D \sqrt{\rho_{o} / \rho_{\infty}} .
$$

Houf and Winters developed a model for a high-momentum, cryogenic hydrogen release [24]. The conditions in the experiment were simulated using this model (neglecting zone 2), and the mole fraction at $X_{i g n}$ was extracted from the simulations. Calculated mole fraction at the maximum ignition distance is plotted as a function of the release temperature in Fig. 5. There does not seem to be a significant trend in terms of temperature (perhaps a slight increase in mole fraction as the release gas warms) or pressure (shown by the size of the symbols). As shown by 
the box plot to the right of the axes, $90 \%$ of the data falls between a mole fraction of 0.13 and 0.18 , with the majority of the outliers towards the higher mole fractions, and, with the $0.75 \mathrm{~mm}$ orifice giving the highest calculated mole fractions at the ignition point. Schlieren imaging showed some deviation from vertical for the $0.75 \mathrm{~mm}$ orifice, and it is likely that the ignition point is not along the centerline for these releases. An off-axis ignition would occur closer to the release point than an on-axis ignition, leading to a higher calculated mole fraction along the centerline. The mean calculated mole fraction at the ignition point is 0.149 , while the median is 0.142 , and the minimum calculated mole fraction at the ignition point is 0.122 . All of these values are higher than the $11 \%$ boundary observed by Veser et al. [23] for the fast flame regime of horizontal $80 \mathrm{~K}$ hydrogen releases. One potential reason for the higher mole fraction could be buoyancy effects from these vertical jets, as compared to the horizontal jets of Veser et al. [23]. A mean mole fraction above the $4 \%$ lower flammability limit of hydrogen is required to ignite turbulent jets because there are pockets of rich and lean concentrations flowing by the ignition point, and the flame speed in the lean pockets needs to overcome the momentum of the flow. It should be cautioned that the model used to calculate the mole fractions in Fig. 5 has not been validated for cryogenic hydrogen releases, and may require some tuning of the entrainment model. Generating validation data for this model by measuring the mole fractions in the unignited flow will be the subject of our future work. 


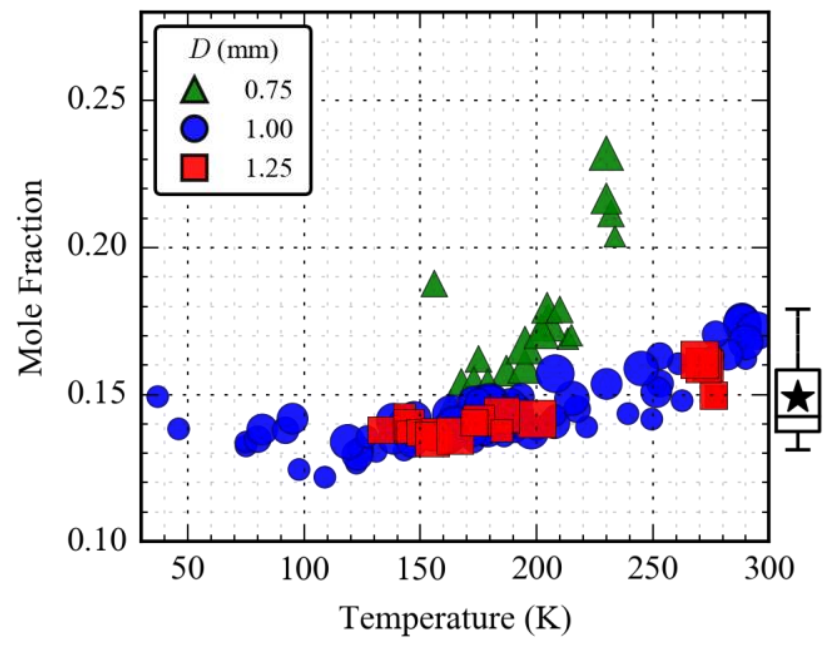

Figure 5. Simulated jet mean hydrogen mole fraction at each ignition point. Points are sized by pressure. Box plot to right of axes shows the median mole fraction (line), quartiles (box edges), 5 and $95 \%$ of the data (whiskers), as well as the mean value (star).

\subsection{Flame Property Measurements: Radiant Power, Length and Width}

Radiant heat flux is a key aspect of flames for the development of hydrogen safety codes and standards. The thermal radiation from a jet flame poses potential threats to the safety of people and infrastructure. To characterize the thermo-physical properties of an ignited underexpanded cryogenic hydrogen jet, the incident radiative power was measured by five wide-angle Medtherm Model 64P-1-22 Schmidt-Boelter thermopile detectors, each with a $150^{\circ}$ view angle. A $\mathrm{Zn}-\mathrm{Se}$ window on the face of each radiometer has $70 \%$ transmission between $0.7-17 \mu \mathrm{m}$. The radiometers were installed at five different locations along the length of the jet flame, and radially 8 inches $(20 \mathrm{~cm})$ away from the jet axis, as shown in Fig. 6. Radiometer measurements were recorded over 1 minute and averaged. In addition to the radiation measurements, visible and IR flame images were recorded to calculate the flame length $\left(L_{f}\right)$ and flame width $\left(W_{f}\right)$, 


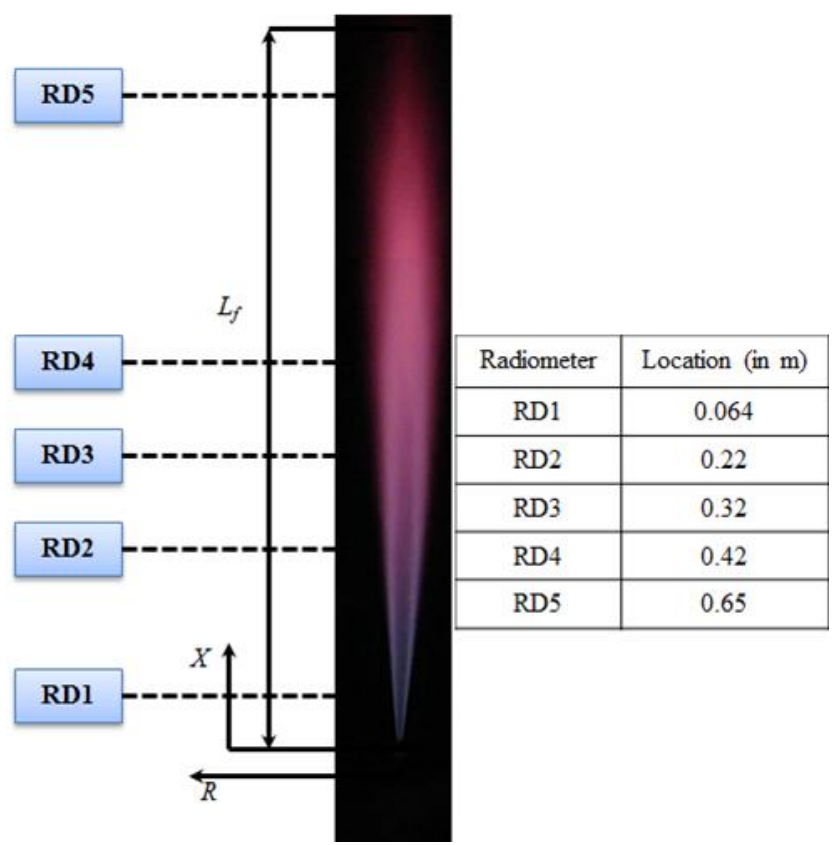

Figure 6. Schematic of the location of the radiometer with respect to an under-expanded jet flame.

which are often used as scaling parameters for the radiative heat flux from a jet flame. The IR images were recorded by a FLUKE TI 400 camera with transmission in the range of $7.5-14 \mu \mathrm{m}$ IR spectral bands. The visible flame images were captured by a commercial Panasonic Lumix camera.

In an experimental study by Kalghatgi [25], measurements of visible flame lengths, for both subsonic and under-expanded jet flames, were observed to have a linear dependence on the mass flow rate. They also determined that a flame grows with nozzle diameter at a fixed mass flow rate. More recently, in a series of experiments at cryogenic temperatures of $34-65 \mathrm{~K}$ and pressures of $7-30$ bars, Friedrich et al. [9] reported that when a cryogenic under-expanded hydrogen jet is ignited leading to a jet flame, the measured heat flux scales with the hydrogen mass flow rate. However, these data did not demonstrate the dependence of the flame length or the radiative heat flux on the release temperature of the under-expanded hydrogen jets. In the 
current study, the effect of the hydrogen temperature at the nozzle on the radiative properties of the jet flame was quantified by systematically varying it from room temperature $(295 \mathrm{~K})$ to near the saturation temperature $(37 \mathrm{~K})$. Figure 7 compares the time averaged IR image and visible image of a $1 \mathrm{~mm}$ diameter cryogenic hydrogen jet released at nozzle pressure and temperature of 2 bar and $55 \mathrm{~K}$, respectively. The flame is vertically oriented with the nozzle

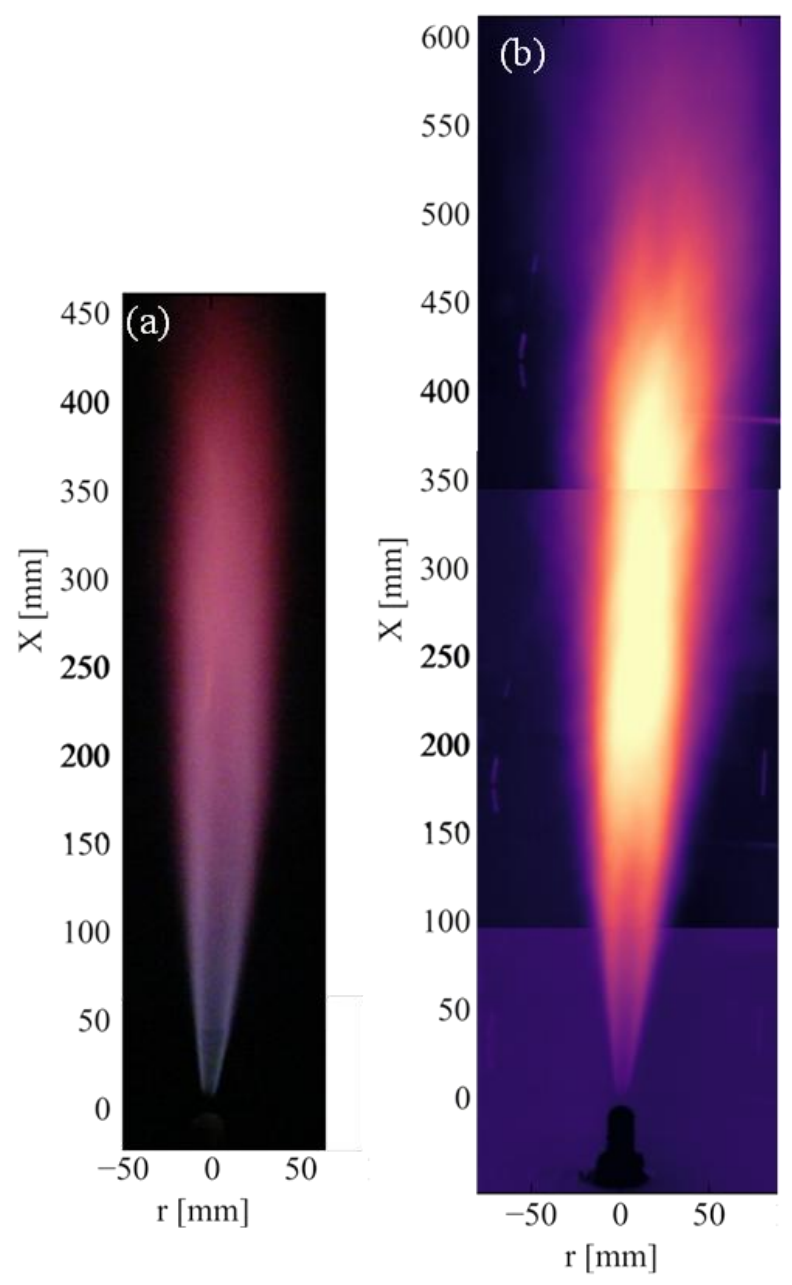

Figure 7. (a) Visible and (b) IR flame image for a cryogenic under-expanded hydrogen flame.

Source is a $1 \mathrm{~mm}$ diameter nozzle at 2 bar $_{\mathrm{abs}}$ and $55 \mathrm{~K}$.

center at $\mathrm{r}=0 \mathrm{~mm}$ and $\mathrm{x}=0 \mathrm{~mm}$ of the image. The field of view for the IR camera was $0.28 \mathrm{~m}$; the vertical stage was traversed in steps of $0.2 \mathrm{~m}$; a series of five IR images were averaged at 


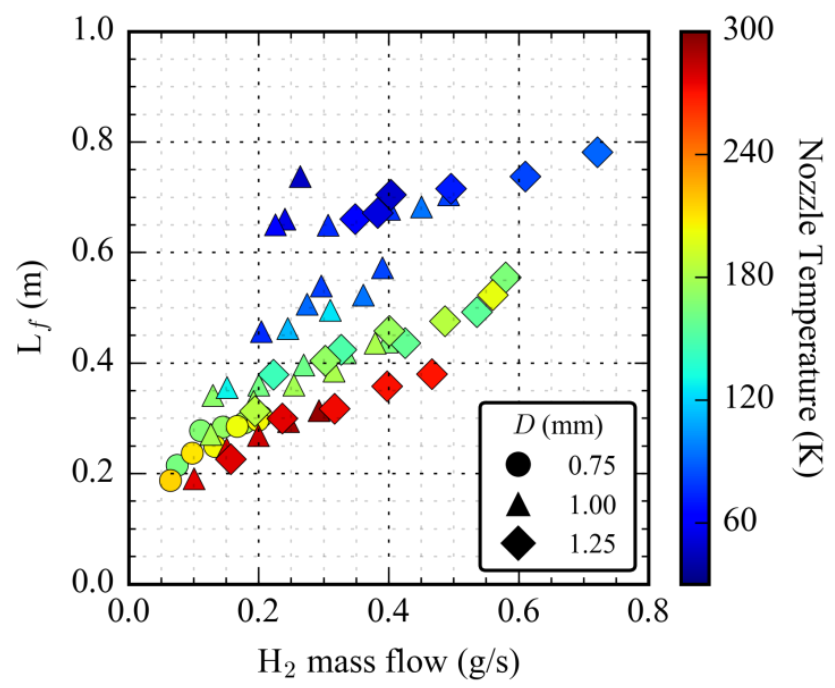

Figure 8. Flame length as a function of mass flow rate.

every location to construct the entire flame length. For each of the IR and visible images, flame length corresponds to the distance from the nozzle exit (along the axis of the flame) where the intensity drops to $10 \%$ of the maximum intensity level for that image. Reported flame length and width are the average of the IR and visible values. Figure 8 shows the variation of flame length extracted from the images as a function of hydrogen mass flow rate. There is an increase in the flame height with hydrogen mass flow rate which agrees with the trend reported elsewhere $[9,25]$. However, it is clear that the flame length increases with a decrease in nozzle temperature for a fixed mass flow rate.

Schefer et al. [26] studied hydrogen diffusion flames and defined a dimensionless flame length, $L^{*}$,

$$
L^{*}=L_{f} \frac{f_{s}}{D_{e f f}},
$$

where $L_{f}$ is the measured flame length, $f_{s}$ is the stoichiometric mass fraction and $D_{e f f}$ is the same effective diameter defined in section 3.1. The dimensionless flame length was shown to be dependent on the flame Froude number, which is defined as: 


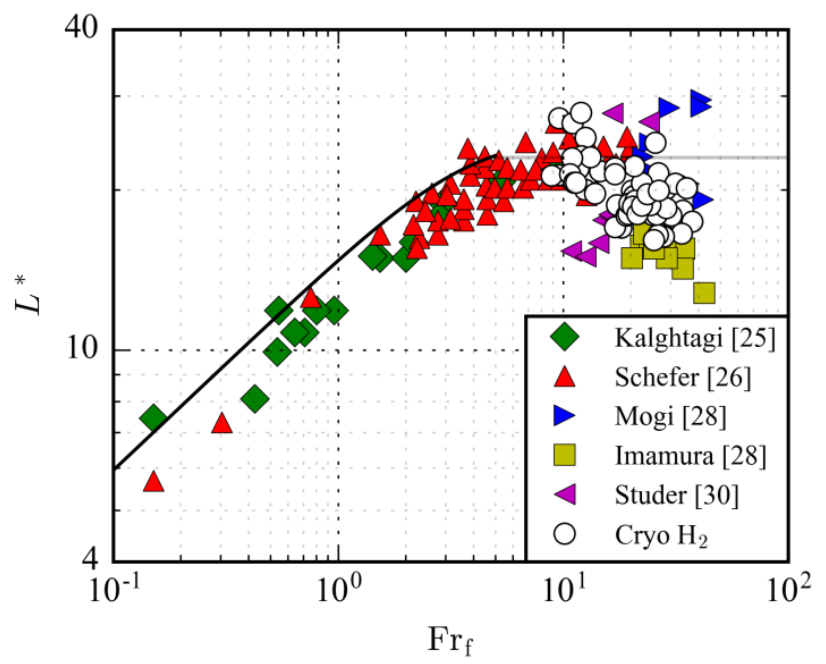

Figure 9. Variation of dimensionless flame length, $L^{*}$, as a function of Froude number, for the cryogenic hydrogen releases for the current study, along with data from literature.

$$
\operatorname{Fr}_{f}=\frac{V_{j} f_{s}^{3 / 2}}{\left(\rho_{e} / \rho_{\infty}\right)^{1 / 4}\left[(g \mathrm{D}) \Delta T_{f} / T_{\infty}\right]^{1 / 2}}
$$

where, $\rho_{e} / \rho_{\infty}$ is the ratio of jet gas density to ambient gas density, and $\Delta T_{f}$ is the peak flame temperature rise due to combustion heat release.

For a momentum dominated jet $\left(\mathrm{Fr}_{f}>5\right)$, as all of the flames in this study were, the dimensionless flame length according to Schefer et al. [26] should be, $L^{*}=23$. In Fig. 9, the dimensionless flame lengths measured in this study are compared to the flame lengths of hydrogen diffusion flames reported by different authors. There is a large scatter of the current data around the $L^{*}=23$ line with, $15 \leq L^{*} \leq 30$. This scatter was also reported by Molkov and Saffers [27] when comparing the flame lengths from a wider range of experimental data [25-30]. Based on a similarity analysis to correlate flame length with flow (i.e, density, velocity, viscosity) and geometric variable (i.e, diameter), Molkov and Saffers [27], expressed flame length as a function of mass flow rate $\dot{m}$, diameter, $D$, and jet viscosity, $\mu_{N}$, as 


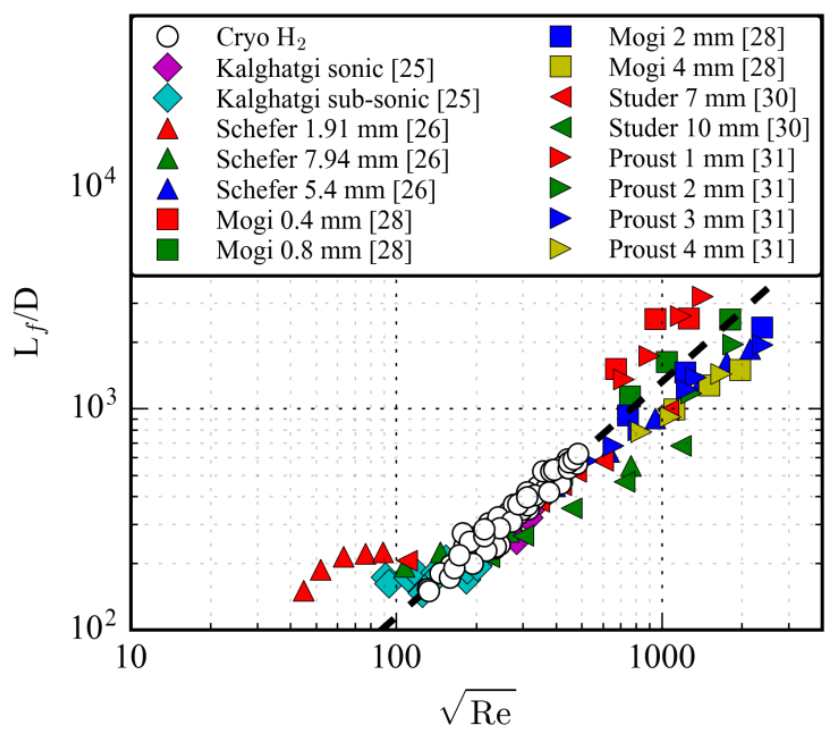

Figure 10. Variation of flame length, $L_{f}$, as a function of Reynolds number, for the cryogenic hydrogen releases for the current study, along with data from the literature.

$$
L_{f}=f\left[\sqrt{\frac{4 \dot{m} D}{\pi \mu_{N}}}\right]=f[D \sqrt{\mathrm{Re}} .]
$$

Since previously reported literature data were atmospheric temperature hydrogen releases, the lack of variations in viscosity allowed the flame length to be shown to scale as, $\sqrt{\dot{m} D}$. Similar to the scaling analysis discussed by Molkov and Saffers [27] in this study we express a normalized flame length, $L_{f} / D$, as a function of the more conventional Reynolds number, Re, (based on the throat density, viscosity, choked flow velocity, and diameter). Figure 10 shows the variation of normalized flame length of the cryogenic hydrogen jet flames from the current study, along with the data from literature [24-25,28-31], as a function of the square root of the Reynolds number. The data collapses on to a line with the equation of the best fit given by

$$
\frac{L_{f}}{D}=0.86 \sqrt{\mathrm{Re}}
$$

The increased scatter for data at larger Reynolds numbers could be due to larger turbulent fluctuations leading to increased experimental uncertainty in measuring flame length. 


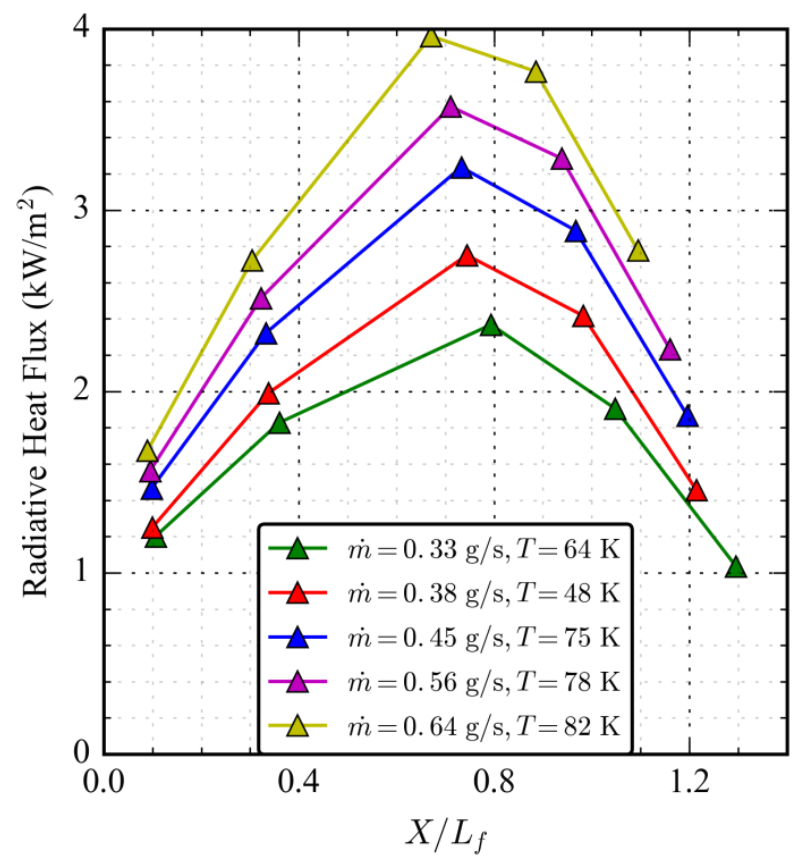

Figure 11. Radiative heat flux along the length of the jet flame, for several cold release conditions.

Figure 11 shows the axial variation of the radiative heat flux emitted by the underexpanded $\mathrm{H}_{2}$ jet flames for five different cryogenic hydrogen releases. The axial locations of the radiometers are normalized by the respective measured flame length, and the peak value in the radiative heat flux is observed at $X / L_{f}$ in the range of $0.7-0.8$. This is an expected behavior for a turbulent jet flame [32]. It is also noticeable that with an increase in $\mathrm{H}_{2}$ mass flow rate there is a corresponding increase in the peak value of the radiative heat flux, regardless of the release temperature. 
Figure 12 shows the variation of radiative heat flux measured by each of the radiometers as a function of hydrogen mass flow rate. There is an increase in the heat flux with an increase in hydrogen mass flow rate. However, for a fixed mass flow rate of hydrogen there is an increase in the radiative heat flux for colder jet releases. The heat flux also increases with the nozzle diameter.
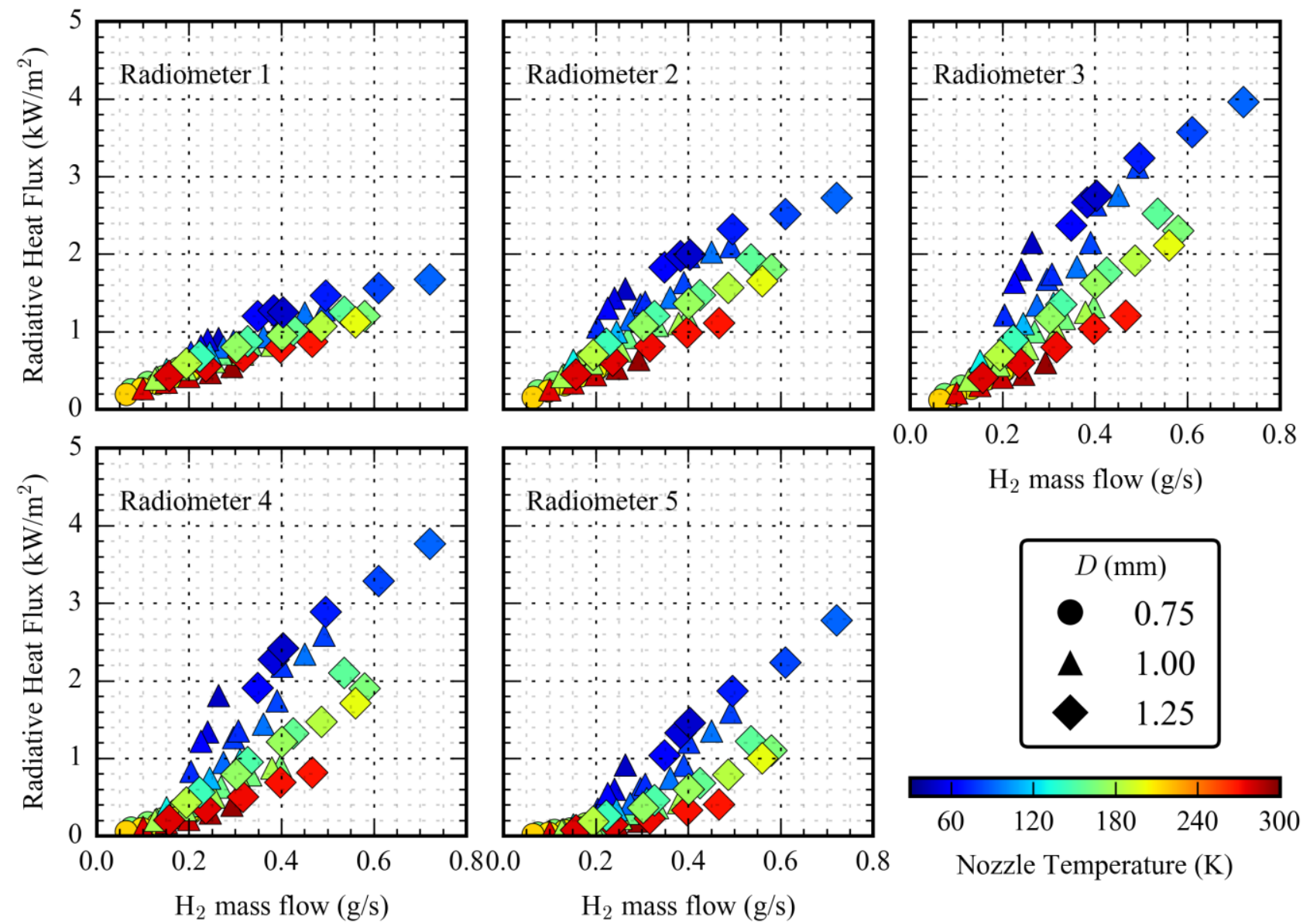

Figure 12. Radiative heat flux measured by each of the radiometers for all the test conditions.

Table 3 summarizes the maximum ignition distance and maximum heat flux measured at 25 representative operating conditions. The stagnation density, nozzle density and speed of sound is calculated by using the real gas equations of state. 
Table 3. Representative cryogenic hydrogen jet release experimental conditions and measured quantities. Experimental uncertainty in the nozzle temperature is $\pm 3 \mathrm{~K}$.

\begin{tabular}{|c|c|c|c|c|c|c|c|c|c|c|}
\hline $\begin{array}{c}\text { TEST } \\
\text { ID } \\
\end{array}$ & $\begin{array}{c}D \\
(m m)\end{array}$ & $\begin{array}{l}T_{n o z} \\
(K)\end{array}$ & $\begin{array}{c}P_{a b s} \\
\text { (bar) }\end{array}$ & $\begin{array}{l}m_{H 2} \\
(g / s)\end{array}$ & $\begin{array}{c}\rho_{o} \\
\left(\mathrm{~kg} / \mathrm{m}^{3}\right)\end{array}$ & $\begin{array}{c}\rho_{\text {noz }} \\
\left(\mathbf{k g} / \mathrm{m}^{3}\right)\end{array}$ & $\begin{array}{c}C_{n o z} \\
(\mathrm{~m} / \mathrm{s})\end{array}$ & $\begin{array}{c}X_{i g n} \\
(\boldsymbol{m m})\end{array}$ & $\begin{array}{c}L_{f} \\
(\boldsymbol{m})\end{array}$ & $\underset{\left(\boldsymbol{k W} / \boldsymbol{m}^{2}\right)}{\left.Q_{\text {rad }}\right)}$ \\
\hline 1 & 0.75 & 163 & 2.00 & 0.080 & 0.30 & 0.19 & 996 & 102 & 0.21 & 0.19 \\
\hline 2 & 0.75 & 179 & 5.00 & 0.178 & 0.68 & 0.43 & 1041 & 127 & 0.29 & 0.57 \\
\hline 3 & 0.75 & 205 & 6.00 & 0.195 & 0.71 & 0.45 & 1107 & 107 & 0.30 & 0.48 \\
\hline 4 & 0.75 & 215 & 2.00 & 0.065 & 0.23 & 0.14 & 1128 & 72 & 0.19 & 0.12 \\
\hline 5 & 1.00 & 46 & 2.00 & 0.250 & 1.08 & 0.70 & 559 & 332 & 0.74 & 2.15 \\
\hline 6 & 1.00 & 55 & 2.00 & 0.241 & 0.89 & 0.58 & 613 & 321 & 0.66 & 1.80 \\
\hline 7 & 1.00 & 62 & 2.00 & 0.230 & 0.79 & 0.51 & 651 & 307 & 0.65 & 1.64 \\
\hline 8 & 1.00 & 78 & 4.00 & 0.375 & 1.25 & 0.81 & 727 & 307 & 0.68 & 2.64 \\
\hline 9 & 1.00 & 81 & 5.00 & 0.460 & 1.51 & 0.98 & 740 & 332 & 0.70 & 3.12 \\
\hline 10 & 1.00 & 113 & 3.00 & 0.240 & 0.64 & 0.41 & 854 & 227 & 0.46 & 1.10 \\
\hline 11 & 1.00 & 124 & 4.00 & 0.297 & 0.78 & 0.50 & 888 & 227 & 0.50 & 1.37 \\
\hline 12 & 1.00 & 127 & 2.00 & 0.147 & 0.38 & 0.24 & 901 & 157 & 0.36 & 0.62 \\
\hline 13 & 1.00 & 163 & 3.00 & 0.200 & 0.45 & 0.28 & 996 & 172 & 0.36 & 0.68 \\
\hline 14 & 1.00 & 175 & 3.00 & 0.195 & 0.41 & 0.26 & 1029 & 147 & 0.33 & 0.57 \\
\hline 15 & 1.00 & 295 & 6.00 & 0.274 & 0.49 & 0.31 & 1312 & 117 & 0.31 & 0.60 \\
\hline 16 & 1.25 & 46 & 2.00 & 0.380 & 1.08 & 0.67 & 571 & 412 & 0.70 & 2.75 \\
\hline 17 & 1.25 & 53 & 2.00 & 0.365 & 0.93 & 0.60 & 601 & 387 & 0.67 & 2.66 \\
\hline 18 & 1.25 & 64 & 2.00 & 0.330 & 0.76 & 0.50 & 661 & 372 & 0.66 & 2.37 \\
\hline 19 & 1.25 & 70 & 3.00 & 0.460 & 1.05 & 0.68 & 690 & 392 & 0.71 & 3.24 \\
\hline 20 & 1.25 & 91 & 5.00 & 0.660 & 1.34 & 0.87 & 778 & 397 & 0.78 & 3.96 \\
\hline 21 & 1.25 & 144 & 2.00 & 0.213 & 0.34 & 0.21 & 944 & 202 & 0.38 & 0.89 \\
\hline 22 & 1.25 & 155 & 5.00 & 0.525 & 0.78 & 0.50 & 978 & 272 & 0.49 & 2.52 \\
\hline 23 & 1.25 & 185 & 2.00 & 0.192 & 0.26 & 0.17 & 1054 & 172 & 0.31 & 0.69 \\
\hline 24 & 1.25 & 200 & 6.00 & 0.540 & 0.72 & 0.46 & 1095 & 237 & 0.52 & 2.11 \\
\hline 25 & 1.25 & 272 & 5.00 & 0.377 & 0.45 & 0.28 & 1261 & 157 & 0.36 & 1.04 \\
\hline
\end{tabular}

In a scaling analysis, Turns and Myer [33] proposed that the radiant fraction, $\chi_{r}$, from a non-premixed turbulent jet flame can be scaled as a function of

$$
\chi_{r}=\frac{S_{r a d}}{\dot{m} \Delta H_{c}} \propto \frac{a_{P} T_{f}^{4} D}{V_{j}},
$$

where $S_{r a d}$ is the total radiative power emitted from the flame, $\Delta H_{c}$ is the heat of combustion, $a_{P}$ is the Planck-mean absorption coefficient for an optically thin flame, $T_{f}$ is the adiabatic flame 


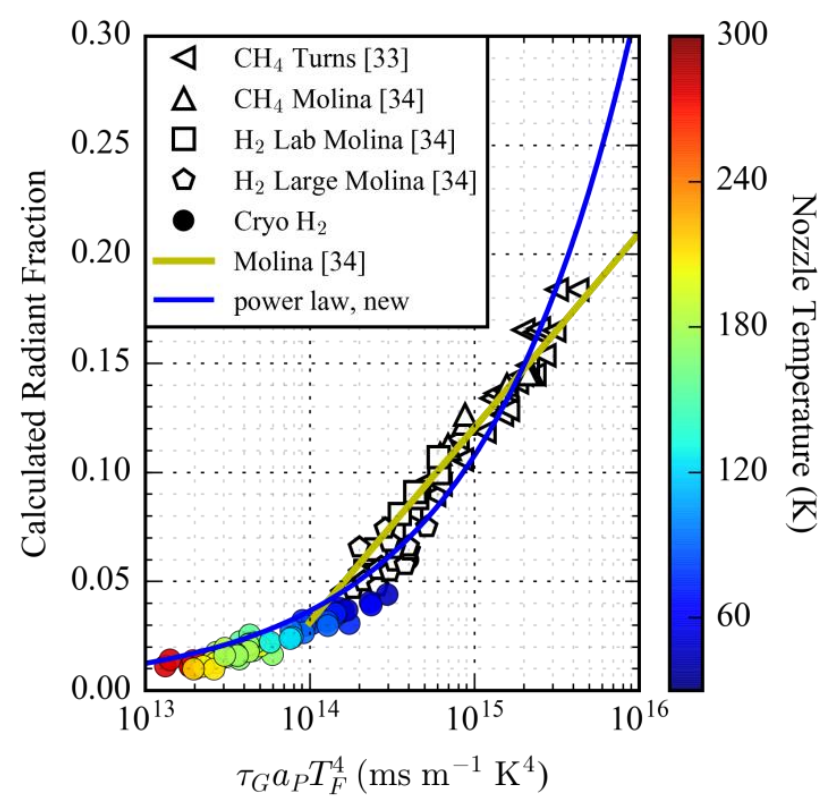

Figure 13. Calculated radiant fractions for the cryogenic hydrogen jet flames.

temperature, $V_{j}$ is the jet exit velocity and $D / V_{j}$, the ratio of the diameter to velocity, is considered to be a flame residence time. The Planck-mean absorption coefficients for the different flames ( 0.23 for hydrogen) are based on the RADCAL calculations reported by Molina et al. [34]. A global flame residence time in terms of the flame geometric parameters and fluid properties was also defined as

$$
\tau_{G}=\frac{\rho_{f} W_{f}^{2} L_{f} f_{s}}{3 \rho_{o} D^{2} V_{j}} .
$$

The radiative fraction for a momentum dominated flame was found to be proportional to the $\log \left(\tau_{G}\right)$. This dependence is evident in Fig. 13, where $\chi_{r}$ is plotted as a function of $a_{P} \tau_{G} T_{f}^{4}$. The data from the current study is compared with the existing data in the literature for hydrogen $\left(\mathrm{H}_{2}\right)$, syngas $\left(\mathrm{CO} / \mathrm{H}_{2}\right)$ and methane $\left(\mathrm{CH}_{4}\right)$ flames [26,33-34]. The majority of the flame residence times of the cryogenic hydrogen jet flames studied here are smaller than the under-expanded and lab scale hydrogen jet flames observed previously. Nonetheless, a trend continues into this region. This trend is different than the logarithmic correlation that the data previously suggested, 
shown by the yellow line in the plot [34]. A correlation based on power-law is proposed to predict the radiative fraction as a function of global flame residence time, given as

$$
\chi_{r}=9.45 \times 10^{-9}\left[a_{P} \tau_{G} T_{f}^{4}\right]^{0.47}
$$

Now focusing on the radiant fraction data from the current study, the highest radiant fractions are seen for the lowest temperature releases. The speed of sound decreases as the temperature decreases. The nozzle exit velocity is equal to the speed of sound for all the choked, under-expanded jet flames studied herein. As shown in Eq. (7), as the velocity decreases, the global residence time increases, and there is a corresponding increase in the radiant fraction. This is an important finding with respect to the safety associated with cryogenic hydrogen infrastructure. The increased radiant fraction and total radiative power from these cryogenic releases over room temperature releases must be accounted for in the analysis of these systems.

\subsection{Summary and Conclusions}

Understanding the safety distances for ignition sources, and the radiative heat flux from a turbulent-jet flame release or flame issuing from a hydrogen storage system leak are issues of importance for the safe use of hydrogen. While there is extensive literature on high-pressure hydrogen jet-flames, there is a scarcity of data on cryogenic systems. In this work, cryogenic under-expanded hydrogen jet flames were investigated over a range of temperature (37-295 K), pressure (2-6 bar $\left._{a b s}\right)$ and nozzle release diameters $(0.75-1.25 \mathrm{~mm})$. Measurements included the maximum ignition distance, the flame length, and the radiative heat flux.

Under-expanded hydrogen jets were ignited with the help of a laser spark focused along the jet centerline. The experimental release, at a fixed pressure and temperature, was moved, bringing the spark closer to the nozzle, until a jet flame ignited. This maximum ignition distance is greater for colder, cryogenic jets at a fixed hydrogen mass flow rate, than for room 
temperature jets. However, there is a linear dependence of the maximum ignition distance with the jet effective diameter. The mean hydrogen mass fraction along the centerline and the air entrainment rate both scale linearly with the effective diameter. The ignitability of a fuel-air mixture depends on the local mass fraction of the fuel, justifying the correlation between ignition distance and effective diameter. A model was applied to these releases and the mean mole fraction at ignition is approximately 0.14 (with $90 \%$ of the data between 0.13 and 0.18 ), with negligible dependence on temperature.

The hydrogen jet flame length (normalized by the release diameter) is linearly dependent on the square root of jet Reynolds number, for cryogenic, as well as room temperature sources of hydrogen. This observation is similar to the findings by Molkov and Saffers [27].The maximum radiative heat flux is emitted at approximately $70-80 \%$ of the flame length. For a fixed hydrogen mass flow, the radiative heat flux increases as the release temperature decreases. This is due to the lower choked flow velocity of the colder hydrogen source increasing the flame residence time. This study provides critical information with regard to the development of guidelines for safety codes and standards of hydrogen infrastructure.

\subsection{Acknowledgement}

Thanks to Radoslav Bozinoski for his implementation of the COLDPLUME model in Python. This research was supported by the United States Department of Energy Fuel Cell Technologies Office, under the Safety, Codes, and Standards subprogram element managed by Will James. Sandia National Laboratories is a multi-program laboratory managed and operated by Sandia Corporation, a wholly owned subsidiary of Lockheed Martin Corporation, for the U.S. Department of Energy's National Security Administration under contract DE-AC04-94AL85000. 


\subsection{References}

1. Brown T, Schell LS, Stephens-Romero S, Samuelsen S, Economic analysis of near-term California hydrogen infrastructure. International Journal of Hydrogen Energy, 2013; 38:3846-57.

2. Hydrogen Technologies Code, National Fire Protection Agency, NFPA 2, Quincy MA, 2016.

3. Ekoto IW, Hecht E, San Marchi C, Groth KM, Lafleur AC, Natesan N, Ciotti M, Harris A. Liquid Hydrogen Release and Behavior Modeling: State-of-the-Art Knowledge Gaps and Research Needs for Refueling Infrastructure Safety. Tech. rep. SAND2014-18776. Sandia National Laboratories; 2014.

4. Hooker P, Willoughby DB, Experimental releases of liquid hydrogen. Proc $4^{\text {th }}$ International Conference on Hydrogen Safety, San Francisco, CA, USA, Sept 12 - 14, 2011

5. Royle M, Willoughby D, The safety of the future hydrogen economy. Process Saf Environ, 2011;89:452-62.

6. Kotchourko A, Baraldi D, Benard P, Jordan T, Kessler A, LaChance J, Molkov V, Steen M, Tchouvelev A. State-of the-Art and Research Priorities in Hydrogen Safety. Proc 5th International Conference on Hydrogen Safety, Brussles, Belgium, Sept 9-11, 2013.

7. Hall JE, Hooker P, Willoughby D. Ignited releases of liquid hydrogen: Safety considerations of thermal and overpressure effects. International Journal of Hydrogen Energy. 2014; 39(35):20547-53.

8. Statharas JC, Venetsanos AG, Bartzis JG, Würtz J, Schmidtchen U. Analysis of data from spilling experiments performed with liquid hydrogen. Journal of Hazardous Materials. 2000; 77(1):57-75.

9. Friedrich A, Breitung W, Stern G, Veser A, Kuznetsov M, Fast G, Oechsler B, Kotchourko N, Jordan T, Travis JR, Xiao J. Ignition and heat radiation of cryogenic hydrogen jets. International Journal of Hydrogen Energy. 2012; 37(22):17589-98.

10. Giannissi SG, Venetsanos AG, Markatos N, Bartzis JG. CFD modeling of hydrogen dispersion under cryogenic release conditions. International Journal of Hydrogen Energy. 2014; 39(28):15851-63.

11. Houf W, Schefer R. Analytical and experimental investigation of small-scale unintended releases of hydrogen. International Journal of Hydrogen Energy. 2008; 33(4):1435-44. 
12. Ruggles AJ, Ekoto IW. Experimental investigation of nozzle aspect ratio effects on underexpanded hydrogen jet release characteristics. International Journal of Hydrogen Energy. 2014; 39(35):20331-8.

13. Ruggles AJ, Ekoto IW. Ignitability and mixing of underexpanded hydrogen jets. International Journal of Hydrogen Energy. 2012; 37(22):17549-60.

14. Schefer RW, Houf WG, Williams TC. Investigation of small-scale unintended releases of hydrogen: momentum-dominated regime. International Journal of Hydrogen Energy. 2008; 33(21):6373-84.

15. LaChance J. Risk-informed separation distances for hydrogen refueling stations. International Journal of Hydrogen Energy. 2009; 34(14):5838-45.

16. Bell IH, Wronski J, Quoilin S, Lemort V. Pure and pseudo-pure fluid thermophysical property evaluation and the open-source thermophysical property library CoolProp. Industrial \& Engineering Chemistry Research. 2014; 53(6):2498-508.

17. Phuoc TX, White CM, McNeill DH. Laser spark ignition of a jet diffusion flame. Optics and Lasers in Engineering. 2002; 38(5):217-32.

18. Ricou FP, Spalding DB. Measurements of entrainment by axisymmetrical turbulent jets. Journal of Fluid Mechanics. 1961; 11(01):21-32.

19. Han D, Mungal MG. Direct measurement of entrainment in reacting/nonreacting turbulent jets. Combustion and Flame. 2001; 124(3):370-86.

20. Li X, Hecht ES, Christopher DM. Validation of a reduced-order jet model for subsonic and underexpanded hydrogen jets. International Journal of Hydrogen Energy. 2016; 41(2): 13481358.

21. Schefer RW, Evans GH, Zhang J, Ruggles AJ, Greif R. Ignitability limits for combustion of unintended hydrogen releases: Experimental and theoretical results. International Journal of Hydrogen Energy. 2011; 36(3):2426-35.

22. Ruggles AJ. Statistically advanced, self-similar, radial probability density functions of atmospheric and under-expanded hydrogen jets. Experiments in Fluids. 2015; 56(11):1-25.

23. Veser A, Kuznetsov M, Fast G, Friedrich A, Kotchourko N, Stern G, Schwall M, Breitung $\mathrm{W}$. The structure and flame propagation regimes in turbulent hydrogen jets. International Journal of Hydrogen Energy. 2011; 36(3):2351-9.

24. Houf WG, Winter WS. Simulation of high-pressure liquid hydrogen releases.” International Journal of Hydrogen Energy. 2013; 38:8092-99. 
25. Kalghatgi GT. Lift-off heights and visible lengths of vertical turbulent jet diffusion flames in still air. Combustion Science and Technology. 1984; 41(1-2):17.

26. Schefer RW, Houf WG, Bourne B, Colton J. Spatial and radiative properties of an openflame hydrogen plume. International Journal of Hydrogen Energy. 2006; 31(10):1332-40.

27. Molkov V, Saffers JB. Hydrogen jet flames. International Journal of Hydrogen Energy. 2013; 38(19):8141-58.

28. Mogi T, Nishida H, Horiguchi S. Flame Characteristics of high-pressure hydrogen gas jet. In: Proceedings of the 1st International Conference on Hydrogen Safety, Pisa; 2005.

29. Imamura T, Hamada S, Mogi T, Wada Y, Horiguchi S, Miyake A, et al. Experimental investigation on the thermal properties of hydrogen jet flame and hot currents in the downstream region. International Journal of Hydrogen Energy 2008;33:3426

30. Studer E, Jamois D, Jallais S, Leroy G, Hebrard J, Blanchetie`re V. Properties of large-scale methane/hydrogen jet fires. International Journal of Hydrogen Energy 2009; 34: 9611.

31 Proust C, Jamois D, Studer E. High pressure hydrogen fires. Proceedings of the Third International Conference on Hydrogen Safety, 16-18 September 2009, Ajaccio, France, Paper $214 ; 2009$.

32. Houf W, Schefer R. Predicting radiative heat fluxes and flammability envelopes from unintended releases of hydrogen. International Journal of Hydrogen Energy. 2007; 32(1):136-51.

33. Turns SR, Myhr FH. Oxides of nitrogen emissions from turbulent jet flames: Part I-Fuel effects and flame radiation. Combustion and Flame. 1991; 87(3):319-35.

34. Molina A, Schefer RW, Houf WG. Radiative fraction and optical thickness in large-scale hydrogen-jet fires. Proceedings of the Combustion Institute. 2007; 31(2):2565-72. 